\title{
Experimental Study on Partial Replacement of Bitumen with Lignin
}

\author{
Anjana Ramesh, Anitha P A, Joel Francis K J, \\ Kenaz Basil \\ Department of Civil Engineering \\ NSS College of Engineering \\ Palakkad, India
}

\author{
Deepthy S Nair \\ Assistant Professor \\ Department of Civil Engineering \\ NSS College of Engineering \\ Palakkad, India
}

\begin{abstract}
Bitumen is produced from fossil sources, and the asphalt market is looking for alternatives with higher sustainability in terms of low Carbon dioxide emission. The usage of alternative sustainable binders, which can (partly) replace the bitumen, contributes to reduce Carbon dioxide emissions. The alternative polymer that will be used as a "partly" alternative for bitumen originates from nature and is called lignin.

Lignin is one of the most abundant naturally occurring polymers (next to cellulose and hemi cellulose) present in plant material. The chemical structure of lignin known to us today does reflect the structure of bitumen and therefore it could be used as an alternative for bitumen.
\end{abstract}

Keywords- Bio-based, lignin, sustainable, alternative for bitumen, partial replacement, emmissions

\section{INTRODUCTION}

Bio-based waste is used to improve properties (lifetime of the material) and environmental sustainability by shifting from fossil based resources to bio-based resources. Biobased resources are in favor from the sustainability point of view: they are renewable and do not contribute to climate change, as Carbon dioxide captured from the atmosphere as a result of photosynthesis in the original vegetal source. As bitumen is produced from fossil sources the asphalt market is looking for alternatives with higher sustainability in terms of Carbon dioxide emission. The usage of alternative sustainable binders, which can (partly) replace the bitumen, contributes to reduce Carbon dioxide emissions. Another challenge for the bitumen industry is that the petrochemical industry is becoming more and more efficient in breaking down higher chain hydrocarbons to lower chain hydrocarbons with higher added value than bitumen. This has an effect on the availability and quality of bitumen. The use of alternative sustainable binders broadens the availability. The alternative polymer that has been researched as a "partly" alternative for bitumen originates from nature and is called lignin. Lignin is one of the most abundant natural polymers (next to cellulose and hemi cellulose) present in plant material. The chemical structure known today does reflect the structure for bitumen and therefore it could be used as an alternative for bitumen in applications like roofing or asphalt. Not only native lignin's but also modified lignin's have been researched. These modifications were performed to meet original binder (bitumen) properties or to improve binder properties.
Bio-based assets are in support from the maintainability perspective: they are renewable and don't add to environmental change, as Carbon dioxide is caught from the climate subsequently of photosynthesis in the first vegetal source. As bitumen is created from fossil sources the black-top market is searching for options with higher maintainability as far as Carbon dioxide emanation. The utilization of option reasonable folios, which can (somewhat) supplant the bitumen, adds to lessen Carbon dioxide discharges. The option that has been investigated as an "incompletely" elective for bitumen begins from nature and is called lignin. Lignin is a standout amongst the most inexhaustible common polymers (by cellulose and semi cellulose) show in plant material. The substance structure known today reflects the structure for bitumen and along these lines it could be utilized as an option for bitumen in applications like material or black-top. The experiment is to depict the confirmation of idea in utilizing lignin, as substitution or fractional substitution of bitumen without losing its usefulness.

\section{MATERIALS USED}

\begin{abstract}
A.BITUMEN
Bitumen is cementations, amorphous, thermoplastic material and its stiffness is dependent on temperature, its black or dark in colour that is found in different forms, such as rock asphalt, natural bitumen derived from oil. Bureau of Indian Standards (BIS) in year 1950 for the first time introduced paving grade bitumen specifications and classified it on penetration (IS: 731950) and were revised in the years 1962 and 1992. BIS revised (IS: 73-1992) specifications based on Viscosity (at a temp $60^{\circ} \mathrm{C}$ ) in 2006 July to improve some qualities of bitumen. As per these specifications, there are four grades VG-10, VG20 , VG-30 \& VG-40. Presently about $90-95 \%$ of the total road length globally is paved with bitumen. And the overall demands for the bitumen accounts for about 100 million tons per year i.e., about more than 700 million barrels are consumed annually. The majority of asphalt used commercially is obtained from petroleum. Nonetheless, large amounts of asphalt occurring concentrated form in nature. Naturally occurring deposits of bitumen are formed from the remains of ancient, microscopic algae (diatoms) and other once-living things.
\end{abstract}




\section{CHARACTERISTICS:}

\section{- BITUMENADHERES}

Bitumen has good glue qualities under certain conditions. Still in presence of water the bond creates a few issues. The greater part of the totals utilized as a part of street development has a powerless negative charge at first glance. The bitumen total bond is a result of a frail scattering power. Water is profoundly polar and subsequently gets firmly connected to the total uprooting the bituminous covering.

\section{- ELASTICITY}

When a string is taken from a bitumen sample and extends or prolongs it, it can return to a length near its unique length in the long run. For a few bitumen this procedure may take longer time than others. This tendency is called as the flexibility of bitumen.

\section{- PLASTICITY}

At the point when temperatures are increased, and in addition when a heap was connected to bitumen, the it will stream, however won't come back to its original position after load is expelled. This condition was alluded to as plastic conduct. Applying a heap implies that you put a weight on the bitumen keeping in mind the end goal to subject it to stretch. This could be in a lab or in the bitumen last position in the street and it is done to evaluate the bitumen response to the heap.

\section{- VISCO-ELASTIC}

Bitumen is a Visco elastic substance. It might be either thick or versatile relying upon the temperature or the heap it is conveying. At greater temperatures there is more stream or plastic conduct, while at lower temperatures and brief length stacking, the bitumen has a tendency to be firm and flexible. In middle of the road temperatures it has a tendency to be a blend of the two.

\section{B.LIGNIN}

Lignin is an organic binding material that binds the cells, fibers and vessels which constitute wood and the lignified elements of plants, as in straw. It is the second most abundant renewable carbon source on Earth. About 40 and 50 million tons of lignin are produced worldwide as a mostly non commercialized waste product annually. The lignols that crosslink are of three main types, all derived from phenylpropane: 4-hydroxy-3methoxyphenyl propane, 3, 5-dimethoxy-4hydroxyphenylpropane, and 4-hydroxyphenylpropane. The former tends to be more prevalent in conifers and the latter in hardwoods. There are two principal categories of lignin: those which are sulphur bearing and those which are sulphur-free. It is the sulphur bearing lignin's which have to date been commercialized. These include lignosulphonates (world annual production of 500,000 tons) and Kraft lignin's (under 100,000 tons p.a.). Due to the lack of suitable industrial processes, the sulphur-free lignin's are as yet non-commercialized. As a natural and renewable raw material, obtainable at an affordable cost, lignin's substitution potential extends to any products currently sourced from petrochemical substances. It is not possible to define the precise structure of lignin as a chemical molecule. All lignin's show a certain variation in their chemical composition. However the definition common to all is a dendritic network polymer of phenyl propene basic units. The lignin used for the experiment is Sodium lignosulphonate which has a specific gravity of 0.5 , density of $0.5 \mathrm{~g} / \mathrm{cm}^{3}$, and molecular weight of $544.5 \mathrm{~g} / \mathrm{mol}$.

\section{- $\quad$ LIGNIN AS BINDER}

Lignosulfonates are an exceptionally powerful and sparing cement, going about as a coupling operator or "paste" in pellets or compacted materials. Lignosulfonates utilized on unpaved streets lessen ecological worries from airborne clean particles and balance out street surface. The coupling capacity makes it a valuable part of: Coal briquettes, Biodegradable Plastic, Plywood and molecule board, Earthenware production, Creature bolster pellets, Carbon dark, Fiberglass protection, Manures and herbicides tile glue, clean suppressants, and Soil stabilizers

\section{- $\quad$ LIGNIN AS DISPERSANT}

Lignosulfonate keeps the bunching and settling of undissolved particles after suspensions. By joining the molecule surface, it shields the molecule from being pulled in to different particles and lessens the measure of water expected to utilize the item successfully. The scattering property makes lignosulfonate helpful in: Leather tanning, Cement mixes, Concrete admixtures, Clay and ceramics, Dyes and pigments, Pesticides and insecticides.

\section{- $\quad$ LIGNIN AS AN EMULSIFIER}

Lignosulfonate balances out emulsions of nonsoluble fluids, for example, water and oil, making them profoundly impervious to breaking. Lignosulfonates are grinding away as emulsifiers in: Pesticides, Asphalt emulsions, Wax emulsions, Pigments and dyes.

\section{III.BLENDING}

The first blending experiments with lignin were performed by blending the lignin by hand, gradually adding the lignin in powder form and increasing the blending temperature during the adding of the lignin to the bitumen. Based on the first blending procedure experience the procedure for blending was modified. To avoid coagulation of the lignin, the adding of the lignin was done by using a sieve. A finer distribution and contact with the bitumen is hereby achieved. The lignin should be equally fine distributed on the bitumen surface. A constant blending temperature, tuned on the different bitumen types, was applied resulting in homogeneous blends.

\section{IV.MODIFICATION OF LIGNIN}

Compared to bitumen lignin has a high amount of hydroxyl groups. To make lignin even more hydrophobic and more compatible with bitumen the hydroxyl groups present in the lignin have been blocked by using hydrophobic substituents. Several modification routes have been explored using commercially available epoxide containing reactants under alkaline conditions. An epoxide with a more aromatic character, FGE 
(Phenylglycidyl ether), has been used; and an epoxide with a more aliphatic character, EGE (Ethylhexylglycidyl ether), has been used. The lignin used for the chemical modification was the Organosolv lignin. The modified lignin's were blended with the 70/100 bitumen resulting in $25 \%(\mathrm{w} / \mathrm{w})$ of modified lignin. The result of these modifications is that indeed the modified lignin's were easily blended. The modification might even help to increase the amount of lignin that can be blended with the bitumen.

\section{LABORATORY TESTS ON BINDERS}

\section{A.PENETRATION TEST}

The penetration test determines the relative hardness or consistency of the binder by measuring the distance that a standard needle will penetrate vertically into the sample under specified conditions of time, temperature and loading. Standard penetration, which is implied unless other conditions are stated, is for a load of $100 \mathrm{~g}$ applied for 5 seconds at a temperature of $77^{\circ} \mathrm{F}\left(25^{\circ} \mathrm{C}\right)$ (ASTM Test D5). Softer materials have higher penetration values. Other test conditions used are $32^{\circ} \mathrm{F}$ $\left(0^{\circ} \mathrm{C}\right) 200 \mathrm{~g}, 60 \mathrm{sees}$, and $115^{\circ} \mathrm{F}\left(46^{\circ} \mathrm{C}\right) 50 \mathrm{q}, 5$ sees.

Table 1. Penetration Reading

\begin{tabular}{|l|l|}
\hline \multicolumn{2}{|c|}{ Penetration Reading } \\
\hline Standard Bitumen & 58 \\
\hline $\begin{array}{l}\text { Bitumen blended with } \\
5 \% \text { of Lignin }\end{array}$ & 59 \\
\hline $\begin{array}{l}\text { Bitumen blended with } \\
10 \% \text { of Lignin }\end{array}$ & 60 \\
\hline $\begin{array}{l}\text { Bitumen blended with } \\
15 \% \text { of Lignin }\end{array}$ & 50 \\
\hline $\begin{array}{l}\text { Bitumen blended with } \\
20 \% \text { of Lignin }\end{array}$ & 35 \\
\hline $\begin{array}{l}\text { Bitumen blended with } \\
25 \% \text { of Lignin }\end{array}$ & 15 \\
\hline
\end{tabular}

\section{B.SOFTENING POINT TEST}

Different grade asphalts soften at different temperatures. The softening point is usually determined by the ring and ball test method (ASTM Test D36). The softening point indicates the temperature at which the binder changes from solid to liquid. In this test, the binder is poured into a brass ring of specified dimensions. The sample thus prepared is suspended in a water bath and a steel ball of specified dimensions and weight is placed in the centre of the sample. The bath is heated at a controlled rate and the temperature at the instant the steel ball reaches the bottom of the glass vessel or steel plate is recorded. This temperature is termed the softening point.

Table 2. Softening Point Reading

\begin{tabular}{|c|c|}
\hline \multicolumn{2}{|c|}{ Softening Point Reading } \\
\hline Standard Bitumen & 50 \\
\hline $\begin{array}{l}\text { Bitumen blended with } 5 \% \\
\text { of Lignin }\end{array}$ & 44 \\
\hline $\begin{array}{l}\text { Bitumen blended with } \\
10 \% \text { of Lignin }\end{array}$ & 47 \\
\hline $\begin{array}{l}\text { Bitumen blended with } \\
15 \% \text { of Lignin }\end{array}$ & 49 \\
\hline $\begin{array}{l}\text { Bitumen blended with } \\
20 \% \text { of Lignin }\end{array}$ & 60 \\
\hline $\begin{array}{l}\text { Bitumen blended with } \\
25 \% \text { of Lignin }\end{array}$ & 70 \\
\hline
\end{tabular}

\section{DUCTILITY TEST}

The ductility test gives a measure of adhesive property of bitumen and its ability to stretch. In flexible pavement design, it is necessary that binder should form a thin ductile film around aggregates so that physical interlocking of the aggregates is improved. Binder material having insufficient ductility gets cracked when subjected to repeat traffic loads and it provides pervious pavement surface.

Ductility of a bituminous material is measured by the distance in centimetres to which it will elongate before breaking when two ends of standard briquette specimen of material are pulled apart at a specified speed and specified temperature.

Table 3. Ductility Reading

\begin{tabular}{|l|l|}
\hline \multicolumn{2}{|c|}{ Ductility Reading } \\
\hline Standard Bitumen & 58 \\
\hline $\begin{array}{l}\text { Bitumen blended with } \\
5 \% \text { of Lignin }\end{array}$ & 59 \\
\hline $\begin{array}{l}\text { Bitumen blended with } \\
10 \% \text { of Lignin }\end{array}$ & 60 \\
\hline $\begin{array}{l}\text { Bitumen blended with } \\
15 \% \text { of Lignin }\end{array}$ & 50 \\
\hline $\begin{array}{l}\text { Bitumen blended with } \\
\text { 20\% of Lignin }\end{array}$ & 35 \\
\hline $\begin{array}{l}\text { Bitumen blended with } \\
25 \% \text { of Lignin }\end{array}$ & 15 \\
\hline
\end{tabular}

The graphs obtained are as follows:

\section{Penetration value}



Fig.1Graph showing \%replacement of bitumen with lignin and penetration value 


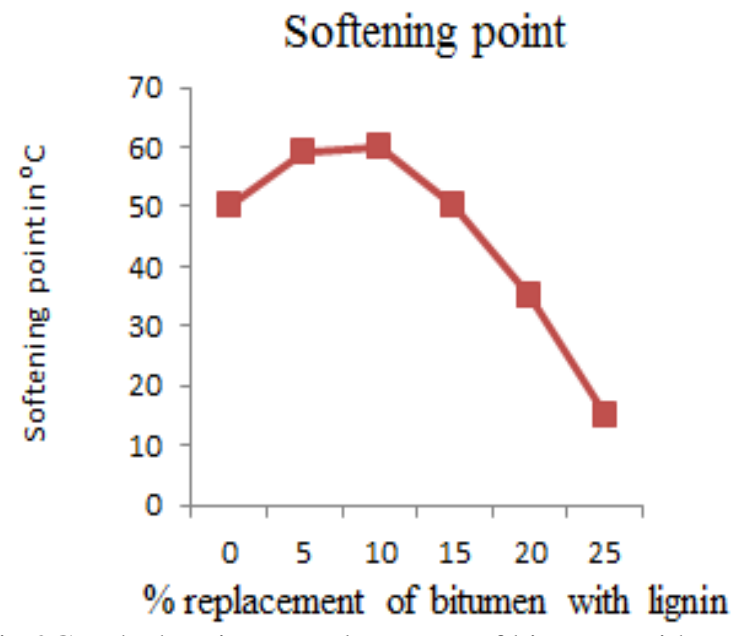

Fig.2Graph showing \%replacement of bitumen with lignin and softening point.



Fig.3Graph showing \%replacement of bitumen with lignin and Ductility value

\section{CONCLUSIONS}

The study were performed using different percentage of replacement of Bitumen with Lignin. The results obtained from the ductility test, penetration test, and softening point test were compared with the standard values of the Bitumen. The conclusions obtained from the test results are:

- As the percentage replacement of Bitumen with Lignin increases, the penetration value first increases gradually and reaches a maximum value of $60 \mathrm{~mm}$. Then it suddenly decreases Fig. 1

- As the percentage of replacement of Bitumen with Lignin increases, at first the softening point increases and then it gradually decreases and reaches a minimum value of $15^{\circ} \mathrm{C}$ in Fig. 2

- As the percentage of replacement of Bitumen with Lignin increases, ductility value decreases, finally there is a sudden increase in the ductility value $(45 \mathrm{~cm})$ in Fig. 3

\section{ACKNOWLEDGMENT}

We thank God, the almighty for his blessings without which nothing would have been possible. We also extend our heartfelt thanks to Deepthy S Nair, Assistant Professor, Department of Civil Engineering, NSS College of Engineering for her cooperation, guidance and most generous help. We extend our thanks to all the faculty members of Civil Engineering Department and to all our friends for their guidance.

\section{REFERENCE}

[1] NaveedFarooz,QashibFayazSofi,Dr.M.S.Mir,LigninAsPartialRepla cement For Bitumen, International Journal of Creative Research Thoughts 2016, IJCRTRIETS005, ISSN: 2320-2882,24-32.

[2] A.Logeshkumaran, Experimental Study on Partial Replacement of Bitumen with Lignin and Plastic,ISSN:2393-8374,2394-0697, Volume-5, Issue-4,2018,35-41

[3] R.SudhaRani, Dr. P.V. Surya Prakash, Performance of Bituminous Mix Blended with Waste Plastic and Sodium Lignosulphonate, IJIRT Volume 5 Issue 3 ISSN: 2349-6002,2018,161-170

[4] Karol J Kowalski, Jan Krol, Piotr Radziszewski, Raquel Casado. Victor Blanco, Domingo Perez, Victor M Vinas, Yvan Brijsse, Mia Frosch, Duy Michael Le, Matt Wayman, Eco-friendly materials for a new concept of asphalt pavement, $6{ }^{\text {th }}$ Transport Research Arena April 18-21, 2016,3582-3591

[5] Dave Van Vliet, Ted Slaghek, Cecile Giezen, Ingrid Haaksman, Lignin as a Green Alternative for Bitumen, $6^{\text {th }}$ Euroasphalt and Eurobitumen Congress, 1-3 June 2016

[6] K B Batista, R P L Padilha, T O Castro, CFSC Silva, MFAS Araujo, High Temperature Low Temperature and Weathing Aging Performance of Lignin Modified Asphalt Binders, Industrial Crops and Products 2018 107-116

[7] Michal Holy, Eva Remisova, Analysis of Influence of Bitumen Composition on the Properties Represented by Empirical and Viscosity, $13^{\text {th }}$ International Scientific Conference on Sustainable, Modern and Safe Transport, May 29-31, 2019

[8] Siksha Swaroopa Kar, Kushboo Arora, Chandra Kant Mani and Dr. P K Jain, $11^{\text {th }}$ Transportation Planning and Implementation Methodologies for Developing Countries, TPMDC 2014, 10-12 December 2014 